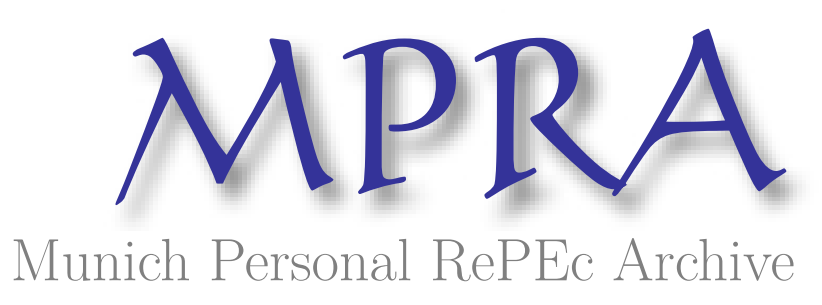

\title{
Incomplete contracts and optimal ownership of public goods
}

Schmitz, Patrick W.

September 2012

Online at https://mpra.ub.uni-muenchen.de/41730/

MPRA Paper No. 41730, posted 05 Oct 2012 16:17 UTC 


\title{
Incomplete contracts and optimal ownership of public goods*
}

\author{
Patrick W. Schmitz \\ University of Cologne, Germany, and CEPR, London, UK
}

\begin{abstract}
The government and a non-governmental organization (NGO) can invest in the provision of a public good. In an incomplete contracting framework, Besley and Ghatak (2001) have argued that the party who values the public good most should be the owner. We show that this conclusion relies on their assumption that the parties split the renegotiation surplus 50:50. If the generalized Nash bargaining solution is applied, then for any pair of valuations that the two parties may have, there exist bargaining powers such that either ownership by the government or by the NGO can be optimal.
\end{abstract}

Keywords: ownership, incomplete contracts, investment incentives, public goods JEL Classification: D23; D86; H41; L31

* Department of Economics, University of Cologne, Albertus-Magnus-Platz, 50923 Köln, Germany. Tel.: +49 221470 5609; fax: +49 221470 5077. E-mail: <patrick.schmitz@unikoeln.de $>$. 


\section{Introduction}

According to the property rights approach to the theory of the firm (Grossman and Hart, 1986; Hart and Moore, 1990; Hart, 1995), when only incomplete contracts can be written, investment incentives are determined by the ownership structure. The optimal ownership structure depends on technological aspects. Specifically, in an otherwise symmetric setting, a party should be the owner if its investments have the largest marginal returns.

In a remarkable contribution, Besley and Ghatak (2001) have applied the property rights approach to discuss who should own public goods. ${ }^{1}$ They consider two parties (the government and a non-governmental organization) who can make non-contractible investments. It turns out that the party who values the public good most should be the owner, regardless of technological aspects.

Besley and Ghatak (2001) assume that the government and the NGO have equal bargaining powers; i.e., they apply the regular Nash bargaining solution so that the renegotiation surplus is split 50:50. In the present paper, we analyze what happens if the generalized Nash bargaining solution is applied, so that the parties' bargaining powers may differ.

It turns out that then for any pair of valuations of the public good that the two parties may have, there exist bargaining powers such that either ownership by the government or by the NGO can be optimal. In particular, if the government (NGO) has all the bargaining power, then ownership by the NGO (government) is optimal.

\footnotetext{
${ }^{1}$ In related settings, Halonen-Akatwijuka and Pafilis (2009) study repeated games, Halonen-Akatwijuka (2012) considers indispensable agents, Francesconi and Muthoo (2011) allow for impure public goods, and Schmitz (2012) introduces asymmetric information.
} 


\section{The model}

There are two parties, $G$ (the government) and $N$ (a non-governmental organization). At some initial date 0, the parties agree on an ownership structure $o \in\{G, N\}$. At date 1 , the parties $G$ and $N$ simultaneously make observable but non-contractible investments $g \geq 0$ and $n \geq 0$, respectively. Following the incomplete contracting approach, it is assumed that ex ante the public good which can be produced with the help of the investments is not yet contractible. ${ }^{2}$

At date 2, the provision of the public good becomes contractible. If the two parties agree to collaborate at date 2 , they together produce the quantity $y(g)+\xi y(n)$ of the public good, ${ }^{3}$ where $y(0)=0, y^{\prime}(0)=\infty, y^{\prime}(\infty)=0$, $y^{\prime \prime}<0$, and $\xi>0$. The parameter $\xi$ indicates whether the government $(\xi<1)$ or the non-governmental organization $(\xi>1)$ has a technological advantage in producing the public good.

If the parties do not collaborate at date 2 , the quantity of the public good depends on the ownership structure. Specifically, in case of disagreement between the parties, the quantity of the public good is $y(g)+\lambda \xi y(n)$ if $o=G$ and $\lambda y(g)+\xi y(n)$ if $o=N$, where $\lambda \in(0,1)$. Hence, while the owner can always realize the full returns of his investments, in case of disagreement he can realize only a fraction $\lambda$ of the returns of the other party's investments (cf. Hart, Shleifer, and Vishny, 1997).

The government's valuation of the public good is given by $\theta_{G}>0$, while the non-governmental organization's valuation is given by $\theta_{N}>0$. Thus, in line with Besley and Ghatak (2001), the parties' payoffs are as illustrated in

\footnotetext{
${ }^{2}$ See Hart and Moore (1999), Maskin and Tirole (1999), and Tirole (1999) for discussions of the incomplete contracting paradigm.

${ }^{3}$ Note that we frame the model in terms of quantities of the public good, while Besley and Ghatak (2001) frame their model in terms of benefits. Whether the model is framed in terms of quantities or benefits makes no economic difference.
} 
Table 1, where $t$ is a (positive or negative) transfer payment from party $N$ to party $G$.

\begin{tabular}{c|cc} 
& payoff of party $G$ & payoff of party $N$ \\
\hline collaboration & $\theta_{G}[y(g)+\xi y(n)]+t$ & $\theta_{N}[y(g)+\xi y(n)]-t$ \\
default, $o=G$ & $\theta_{G}[y(g)+\lambda \xi y(n)]$ & $\theta_{N}[y(g)+\lambda \xi y(n)]$ \\
default, $o=N$ & $\theta_{G}[\lambda y(g)+\xi y(n)]$ & $\theta_{N}[\lambda y(g)+\xi y(n)]$
\end{tabular}

Table 1. The parties' payoffs.

Besley and Ghatak (2001) model the outcome of the ex post negotiations using the regular Nash bargaining solution, so that the renegotiation surplus is split 50:50. In contrast, we model the outcome of the date-2 negotiations using the generalized Nash bargaining solution, where $\pi \in[0,1]$ denotes party $N$ 's bargaining power.

In the incomplete contracting literature, it is useful to make a clear distinction between a party's bargaining position (which refers to the default payoff and is affected by the ownership structure) and a party's bargaining power (which refers to the share of the ex post renegotiation surplus that a party gets). The bargaining position thus corresponds to the disagreement point. While in the regular Nash bargaining solution it is assumed that both parties have the same bargaining power $(\pi=1 / 2)$, in the generalized Nash bargaining solution any $\pi \in[0,1]$ is allowed. ${ }^{4}$ In some contributions to the incomplete contracting literature, it is for simplicity assumed that $\pi=1 / 2$ (for example, see Hart, 1995) or $\pi=1$ (for example, see the main part of Hart and Moore, 1999). By now, several papers allow for any $\pi \in[0,1] .^{5}$ A simple

\footnotetext{
${ }^{4}$ In any case, it is a central assumption of the property rights approach that the bargaining power $\pi$ is independent of the ownership structure (see Hart, 1995, footnote 17).

${ }^{5}$ For example, see Nöldeke and Schmidt (1998), the appendix of Hart and Moore (1999),
} 
non-cooperative foundation for the generalized Nash bargaining solution is a bargaining game in which one party can make a take-it-or-leave-it-offer with probability $\pi$, while the other party can make a take-it-or-leave-it-offer with probability $1-\pi$ (see the appendix of Hart and Moore, 1999). If one models the bargaining process as a full-fledged alternating-offers game following Rubinstein (1982), then the bargaining power $\pi$ can be derived endogenously; in this case it depends on the parties' relative time preferences. Specifically, when a party is relatively more patient, then it has a larger bargaining power. ${ }^{6}$

In accordance with the generalized Nash bargaining solution, the parties will always collaborate and they agree on a transfer payment $t$ such that at date 2 each party gets its default payoff (which it would get in case of disagreement) plus a share of the renegotiation surplus (i.e., the additional surplus that is generated by collaboration). The shares are determined by the parties' bargaining powers. Thus, if $o=G$, then party $G$ 's date-2 payoff is given by

$$
u_{G}^{G}(g, n)=\theta_{G}[y(g)+\lambda \xi y(n)]+(1-\pi) \Delta^{G}(n)
$$

and party $N$ 's date-2 payoff reads

$$
u_{N}^{G}(g, n)=\theta_{N}[y(g)+\lambda \xi y(n)]+\pi \Delta^{G}(n)
$$

where the renegotiation surplus that the parties divide at date 2 is given by

$$
\begin{aligned}
\Delta^{G}(n) & =\left(\theta_{G}+\theta_{N}\right)[y(g)+\xi y(n)-[y(g)+\lambda \xi y(n)]] \\
& =\left(\theta_{G}+\theta_{N}\right)(1-\lambda) \xi y(n) .
\end{aligned}
$$

Che and Hausch (1999), Antràs and Helpman (2004), Schmitz (2006), Ohlendorf (2009), Hoppe and Schmitz (2010), or Ganglmair et al. (2012).

${ }^{6}$ If in an alternating-offers game a player does not accept an offer and instead makes a counteroffer, then the player has to incur the cost of waiting. The smaller is her discount rate, the smaller is this cost. Hence, being more patient confers greater bargaining power. See e.g. Muthoo (1999) for a comprehensive textbook exposition. 
Observe that the renegotiation surplus in case of $G$-ownership depends on party $N$ 's investment only. Note that the transfer payment on which the parties contractually agree at date 2 is $t=\left[(1-\pi) \theta_{N}-\pi \theta_{G}\right](1-\lambda) \xi y(n)$.

Analogously, if $o=N$, then the parties' date-2 payoffs are given by

$$
u_{G}^{N}(g, n)=\theta_{G}[\lambda y(g)+\xi y(n)]+(1-\pi) \Delta^{N}(g)
$$

and

$$
u_{N}^{N}(g, n)=\theta_{N}[\lambda y(g)+\xi y(n)]+\pi \Delta^{N}(g),
$$

respectively, where the renegotiation surplus is given by

$$
\begin{aligned}
\Delta^{N}(g) & =\left(\theta_{G}+\theta_{N}\right)[y(g)+\xi y(n)-[\lambda y(g)+\xi y(n)]] \\
& =\left(\theta_{G}+\theta_{N}\right)(1-\lambda) y(g) .
\end{aligned}
$$

Note that in case of $N$-ownership, the renegotiation surplus depends on party G's investment only. The transfer payment on which the parties contractually agree at date 2 is now $t=\left[(1-\pi) \theta_{N}-\pi \theta_{G}\right](1-\lambda) y(g)$.

\section{The first-best benchmark}

Note that in a first-best world, the parties would always collaborate ex post. Since then the total date- 2 surplus is given by $\left(\theta_{G}+\theta_{N}\right)[y(g)+\xi y(n)]$, the first-best investment levels are implicitly characterized by

$$
\left(\theta_{G}+\theta_{N}\right) y^{\prime}\left(g^{F B}\right)=1
$$

and

$$
\left(\theta_{G}+\theta_{N}\right) \xi y^{\prime}\left(n^{F B}\right)=1
$$

\section{The second-best solution}

We can now analyze the parties' investment incentives in the incomplete contracting world. Given ownership structure $o \in\{G, N\}$, at date 1 party $G$ 
chooses the investment level

$$
g^{o}=\arg \max u_{G}^{o}(g, n)-g
$$

and party $N$ chooses the investment level

$$
n^{o}=\arg \max u_{N}^{o}(g, n)-n .
$$

Hence, under $G$-ownership, the investment levels are implicitly characterized by

$$
\theta_{G} y^{\prime}\left(g^{G}\right)=1
$$

and

$$
\left[\theta_{N} \lambda+\pi\left(\theta_{G}+\theta_{N}\right)(1-\lambda)\right] \xi y^{\prime}\left(n^{G}\right)=1
$$

Under $N$-ownership, the investment levels are characterized by

$$
\left[\theta_{G} \lambda+(1-\pi)\left(\theta_{G}+\theta_{N}\right)(1-\lambda)\right] y^{\prime}\left(g^{N}\right)=1
$$

and

$$
\theta_{N} \xi y^{\prime}\left(n^{N}\right)=1
$$

Note that there is always underinvestment with regard to the first-best solution. Given concavity of the total surplus, this implies that if the investment levels of both parties are larger in one of the ownership structures, then at date 0 the parties will unambiguously agree on this ownership structure.

Now observe that party $G$ invests more under $G$-ownership than under $N$ ownership $\left(g^{G}>g^{N}\right)$ whenever $\theta_{G}>\theta_{G} \lambda+(1-\pi)\left(\theta_{G}+\theta_{N}\right)(1-\lambda)$, which is equivalent to $\pi \theta_{G}>(1-\pi) \theta_{N}$.

Moreover, party $N$ invests more under $G$-ownership than under $N$-ownership $\left(n^{G}>n^{N}\right)$ whenever $\theta_{N} \lambda \xi+\pi\left(\theta_{G}+\theta_{N}\right)(1-\lambda) \xi>\theta_{N} \xi$, which can also be rewritten as $\pi \theta_{G}>(1-\pi) \theta_{N}$.

Thus, the following results hold. 
Proposition 1 Let party $N$ 's bargaining power be given by $\pi$. If $\pi \theta_{G}>(1-$ $\pi) \theta_{N}$, then the optimal ownership structure is $o=G$. If $\pi \theta_{G}<(1-\pi) \theta_{N}$, then the optimal ownership structure is $o=N$.

Corollary 1 (i) Suppose $\pi=1 / 2$. Then the party who values the public good most should be the owner.

(ii) For any given values of $\theta_{G}$ and $\theta_{N}$, the ownership structure $o=G$ is optimal when party $N$ 's bargaining power $\pi$ is sufficiently large, while $o=N$ is optimal if $\pi$ is sufficiently small.

(iii) The optimal ownership structure does not depend on the technology parameter $\xi$.

The results thus show that the central finding of Besley and Ghatak (2001), according to which the public good should be owned by the party who values it most, crucially relies on their assumption that $\pi=1 / 2$. In general, if the government has all the bargaining power, then ownership should be allocated to the NGO. Analogously, if the NGO has all the bargaining power, then the government should be the owner.

Intuitively, increasing the NGO's bargaining power $\pi$ makes $G$-ownership relatively more attractive. The reason is that under $o=G$, the renegotiation surplus $\Delta^{G}(n)$ depends on the NGO's investment only, so that increasing $\pi$ has no effect on the government's investment incentives, while the NGO's investment incentives go up. Moreover, under $N$-ownership the renegotiation surplus $\Delta^{N}(g)$ depends on the government's investment only, so that increasing $\pi$ has no effect on the NGO's investment incentives, while the government's investment incentives decrease. ${ }^{7}$

\footnotetext{
${ }^{7}$ Specifically, consider the case $\pi=1$. Under $G$-ownership, the investment levels are characterized by $\theta_{G} y^{\prime}\left(g^{G}\right)=1$ and $\left[(1-\lambda) \theta_{G}+\theta_{N}\right] \xi y^{\prime}\left(n^{G}\right)=1$, while under $N$ ownership they are characterized by $\theta_{G} \lambda y^{\prime}\left(g^{N}\right)=1$ and $\theta_{N} \xi y^{\prime}\left(n^{N}\right)=1$. Hence, both
} 
Taken together, our findings imply that the important difference between the property rights approach with private goods and public goods is not Besley and Ghatak's (2001) observation that in the latter case ownership should always be allocated to the party that values the public good most, because this observation is true only in the special case in which the government and the NGO have equal bargaining powers. The important difference between the standard private good setting and Besley and Ghatak's (2001) public good setting is the fact that in the latter case it is irrelevant whether the government or the NGO has a technological advantage. ${ }^{8}$

\section{Conclusion}

The property rights approach based on incomplete contracts, which is the leading paradigm in the modern theory of the firm, can also be very useful to throw light on optimal ownership structures in the context of public goods. Yet, the pioneering work of Besley and Ghatak (2001), according to which a public good should always be owned by the party who values it most, may be misleading. In particular in the context of LDCs, the government and the NGO may well have quite different bargaining powers. In this case, it may well be optimal to allocate ownership to the party who has less bargaining power ex post, even if this party does not have a larger valuation for the public good.

the government and the NGO have stronger incentives to invest under $o=G$. Next, consider the case $\pi=0$. Under $G$-ownership, the investment levels are characterized by $\theta_{G} y^{\prime}\left(g^{G}\right)=1$ and $\theta_{N} \lambda \xi y^{\prime}\left(n^{G}\right)=1$, while under $N$-ownership they are characterized by $\left[\theta_{G}+(1-\lambda) \theta_{N}\right] y^{\prime}\left(g^{N}\right)=1$ and $\theta_{N} \xi y^{\prime}\left(n^{N}\right)=1$. Thus, both the government and the NGO have stronger investment incentives under $o=N$.

${ }^{8}$ See, however, Halonen-Akatwijuka (2012) for an interesting recent contribution showing that technological factors can play a role even in the case of public goods. 


\section{References}

Antràs, P., Helpman, E., 2004. Global sourcing. Journal of Political Economy $112,552-580$.

Besley, T., Ghatak, M., 2001. Government versus private ownership of public goods. Quarterly Journal of Economics 116, 1343-1372.

Che, Y.-K., Hausch, D.B., 1999. Cooperative investments and the value of contracting. American Economic Review 89, 125-147.

Francesconi, M., Muthoo, A., 2011. Control rights in complex partnerships. Journal of the European Economic Association 9, 551-589.

Ganglmair, B., Froeb, L.M., Werden, G.J., 2012. Patent hold-up and antitrust: How a well-intentioned rule could retard innovation. Journal of Industrial Economics 60, 249-273.

Grossman, S.J., Hart, O.D., 1986. The costs and benefits of ownership: A theory of vertical and lateral integration. Journal of Political Economy 94, 691-719.

Halonen-Akatwijuka, M., 2012. Nature of human capital, technology and ownership of public goods. Journal of Public Economics, article in press, http://dx.doi.org/10.1016/j.jpubeco.2012.07.005.

Halonen-Akatwijuka, M., Pafilis, E., 2009. Reputation and ownership of public goods. University of Bristol, CMPO Working Paper 09/211.

Hart, O.D., 1995. Firms, Contracts and Financial Structure. Oxford University Press.

Hart, O.D., Moore, J., 1990. Property rights and the nature of the firm. Journal of Political Economy 98, 1119-1158. 
Hart, O., Moore, J., 1999. Foundations of incomplete contracts. Review of Economic Studies 66, 115-138.

Hart, O., Shleifer, A., Vishny, R.W., 1997. The proper scope of government: theory and application to prisons. Quarterly Journal of Economics 112, $1127-1161$.

Hoppe, E.I., Schmitz, P.W., 2010. Public versus private ownership: Quantity contracts and the allocation of investment tasks. Journal of Public Economics 94, 258-268.

Maskin, E., Tirole, J., 1999. Unforeseen contingencies, property rights, and incomplete contracts. Review of Economic Studies 66, 83-114.

Muthoo, A., 1999. Bargaining Theory with Applications. Cambridge University Press.

Nöldeke, G., Schmidt, K.M., 1998. Sequential investments and options to own. Rand Journal of Economics 29, 633-653.

Ohlendorf, S., 2009. Expectation damages, divisible contracts, and bilateral investment. American Economic Review 99, 1608-1618.

Rubinstein, A., 1982. Perfect equilibrium in a bargaining model. Econometrica $50,97-109$.

Schmitz, P.W., 2006. Information gathering, transaction costs, and the property rights approach. American Economic Review 96, 422-434.

Schmitz, P.W., 2012. Public goods and the hold-up problem under asymmetric information. Economics Letters 117, 642-645.

Tirole, J., 1999. Incomplete contracts: Where do we stand? Econometrica $67,741-781$. 